[0212-7199 (2006) 23: 9; pp 438-440] ANALES DE MEDICINA INTERNA Copyright (C) 2006 ARAN EDICIONES, S.L.

AN. MED. INTERNA (Madrid) Vol. 23, N. $^{\circ} 9$, pp. $438-440,2006$

\title{
Linfoma primario de cavidades
}

\author{
P. KHOSRAVI SHAHI, P. SABIN DOMÍNGUEZ, G. PÉREZ MANGA
}

Servicio de Oncología Médica. Hospital General Universitario Gregorio Marañón. Madrid

\author{
PRIMARY EFFUSION LYMPHOMA
}

\section{RESUMEN}

El linfoma primario de cavidades es un linfoma no Hodgkin de fenotipo $\mathrm{B}$ raro, de alto grado, asociado con el virus herpes humano 8 (VHH8), y la mayoría de los casos se dan en el seno de una infección por VIH (SIDA). El pronóstico es pobre, con una mediana de supervivencia menor a los 6 meses. Presentamos el caso de un varón de 65 años, con una hepatopatía crónica de origen incierto, anemia hemolítica crónica y ascitis. La biopsia del peritoneo evidenció un linfoma primario de cavidades. El paciente falleció dos meses después.

PALABRAS CLAVE: LBDCG. Linfoma primario de cavidades. VIH. VHH-8.

\section{ABSTRACT}

Primary effusion lymphoma is a rare high-grade B-cell nonHodgkin's lymphoma associated with human herpesvirus 8 (HHV-8) infection, and is mostly observed in the course of HIV infection (AIDS). The prognosis is poor, with reported median survival time shorter than 6 months. We present a case of a 65-year-old man, with prior unknown origin chronic hepatopathy, chronic hemolytic anaemia, and ascitis. El biopsy of peritoneum showed a primary effusion lymphoma. The patient died two month later.

KEY WORDS: DLBCL. Primary effusion lymphoma. HIV. HHV-8.

Khosravi Shahi P, Sabin Domínguez P, Pérez. Manga G. Linfoma primario de cavidades. An Med Interna (Madrid) 2006; 23: 438-440.

\section{INTRODUCCIÓN}

El linfoma primario de cavidades serosas (LPCS) es una entidad clínico-anatomopatológica bien definida en la última clasificación de las neoplasias hematológicas de la Organización Mundial de la Salud (OMS) del 2001 (1).

El LPCS es una variante infrecuente de los linfomas no Hodgkin (LNH) B difuso de células grandes (LBDCG) (2), que se produce fundamentalmente en el seno de una inmunodepresión profunda, sobre todo en los pacientes infectados por el virus de la inmunodeficiencia humana (VIH positivos). De hecho su aparición en el seno de una infección por VIH define la categoría C de la enfermedad por el VIH (SIDA).

No obstante, también puede aparecer en personas inmunocompetentes y en enfermos mayores con inmunodepresión de otro origen.

$\mathrm{Su}$ agente etiológico es el virus herpes humano-8 (VHH8), que también es el responsable del sarcoma de Kapposi (3).
Desde punto de vista clínico se caracteriza por la aparición de una serositis (pleuritis, pericarditis, peritonitis), con presencia de derrames serosos, sin presencia de una masa tumoral detectable en las cavidades serosas (4). Esta neoplasia se disemina a través de la superficie de las serosas, pudiendo infiltrar otros órganos a distancia, tales como ganglios linfácticos, piel, pulmones o estructuras mediastínicas.

El diagnóstico de la enfermedad resulta difícil de establecer, debido a la rareza de la enfermedad y ausencia de síntomas específicos y de masas detectables.

\section{CASO APORTADO}

Presentamos el caso clínico de un varón de 65 años, sin alergias medicamentosas conocidas, ni factores de riesgo cardiovasculares, que presentaba como antecedentes personales de interés una cirrosis hepática de origen incierto (probablemente alcohólico versus autoin-

Trabajo aceptado: 29 de marzo de 2006

Correspondencia: Parham Khosravi Shahi. Servicio de Oncología Médica. Hospital General Universitario Gregorio Marañón. Dr. Esquerdo, 46.28007 Madrid. e-mail: drkhosravi@hotmail.com 
mune) en grado B de Child (con varias descompensaciones edemoascíticas previas, un episodio de encefalopatía hepática e hipertensión portal con varices esofágicas grado IV, sin hemorragia digestiva previa), cirugía de hernia inguinal derecha, y una anemia hemolítica crónica coombs negativa en estudio.

El paciente ingresa desde urgencias por empeoramiento de su anemia de base y de su estado general, con aparición de síndrome constitucional, fiebre sin focalidad, lesiones cutáneas y nuevo episodio de ascitis.

Durante su ingreso se realiza un estudio complementario amplio que incluye:

Tomografía computerizada (TC) toraco-abdominal que evidencia un hígado con discreta hipertrofia relativa del lóbulo izquierdo y lóbulo caudado en relación con hepatopatía crónica, un área focal de $15 \mathrm{~cm}$ en segmento III de lóbulo izquierdo a descartar hepatocarcinoma, esplenomegalia de $15 \mathrm{~cm}$ de densidad homogénea. Circulación colateral periesofágica, gastroesplénica, mesentérica y recanalización de la vena umbilical. Abundante líquido ascítico con discreto engrosamiento peritoneal difuso. Hernia inguinoescrotal derecha con contenido líquido.

Resonancia magnética del abdomen que muestra una hepatopatía crónica y una lesión hepática hipervascular en segmento III.

Citología y biopsia de lesiones peritoneales que demuestra una neoplasia linfoide atípica con diferenciación plasmablástica y de fenotipo CD20-, CD138+, EMA+, CD38+, CD56-, CD79a-, EBER(VEB), HHV-8+. El estudio molecular realizado mediante la reacción en cadenas de polimerasas (PCR) muestra un reordenamiento monoclonal de los genes de las cadenas pesadas de las inmunoglobulinas (PCR IgH+).

Se realiza biopsia de médula ósea objetivándose un parénquima medular normocelular, sin datos de infiltración neoplásica.

Se realiza biopsia de una de las lesiones cutáneas que objetiva una epidermis intacta. A nivel dérmico superficial se aprecia un infiltrado inflamatorio perivascular constituido por elementos mononucleados, histiocitos y algún eosinófilo. En profundidad, a nivel de la grasa hipodérmica se aprecian elementos atípicos y aislados similares a los presentes en el botón celular del líquido ascítico previo. Estos elementos muestran positividad intensa para EMA y CD43 y en menor grado, para CD78. Las tinciones para CD45, así como para marcadores B (CD19,CD20,CD22,CD79a) y T (CD3) son negativas. El infiltrado dérmico superficial corresponde a una mezcla de histiocitos y elementos de estirpe T (CD4 y CD8), sin aberraciones fenotípicas. Se envío las muestras al CNIO, estableciéndose el diagnóstico definitivo de infiltración hipodérmica por linfoma primario de cavidades.

La serología para VIH y VHC fueron negativo, el estudio de VHB, mostró HbsAg negativo, pero anti-HBc positivo.

En la exploración física destacaba un tinte ictérico de piel y mucosas, la presencia de un soplo sistólico eyectivo en la auscultación cardiaca, semiología ascítica (no a tensión), y una hepatoesplenomegalia, con edemas bimaleolares. Tras la corrección de su anemia mediante trasfusión de concentrados de hematíes recibe el primer ciclo de quimioterapia con esquema CHOP con disminución de dosis debido a la patología concomitante del paciente, junto con lamivudina $100 \mathrm{mg} /$ día por vía oral.

En los días siguientes al ciclo, el paciente presenta hiperglucemias mantenidas que requiere insulina NPH, presentando un deterioro clínico y analítico de las pruebas de función hepática. Además, el paciente desarrolló una encefalopatía hepática grado II que se resuelve posteriormente con tratamiento médico.

Tras el primer ciclo de quimioterapia el paciente requiere transfusión de varios concentrados de hematíes por anemia, y presenta mielotoxicidad con trombopenia moderada y neutropenia grado IV afebril.
El paciente rechaza continuar con el tratamiento, y fallece dos meses después del diagnóstico de la enfermedad por un cuadro de shock séptico de origen biliar.

\section{DISCUSIÓN}

El LPCS es un LNH de fenotipo B de alto grado de agresividad, cuyas células neoplásicas linfoides son de aspecto inmunoblástico, y a veces con rasgos anaplásicos. Estas células expresan un fenotipo aberrante, con ausencia de los antígenos de la clase B (CD19,CD20,CD22, CD79a) y de la expresión de las inmunoglobulinas tanto de superficie (sIg-) como intracitoplasmáticas $(3,5)$.

Sin embargo, dichas células expresan marcadores de células B activadas y/o de células plasmáticas (CD30+, CD38+ y CD138+). El diagnóstico de este subtipo de LBDCG puede resultar muy difícil, y para ello hay que recurrir al análisis del líquido seroso (peritoneal en nuestro caso).

En el líquido seroso (pleural, peritoneal o pericárdico) se puede realizar citología - biopsia, imunofenotipaje mediante el empleo de citometría de flujo, y técnicas de biología molecular como el estudio del reordenamiento clonal de los genes de las cadenas pesadas de las inmunoglobulinas (PCR $\operatorname{IgH}$ ).

El PCR IgH positivo demuestra el origen monoclonal de la enfermedad a partir de linfocitos B. Además hay que realizar un estudio de extensión para descartar la afectación secundaria de otros órganos, como TC toraco-abdominal, aspiradobiopsia de médula ósea, biopsia de posibles adenopatías o lesiones secundarias (cutáneas en nuestro caso).

El genoma del virus VHH-8 se suele encontrar integrado en el DNA de las células tumorales (presente en nuestro caso), y su detección mediante técnica de hibridación in situ (FISH) permite establecer el diagnóstico de la enfermedad.

El pronóstico de esta variante de LBDCG es ominoso, con una mediana de supervivencia global generalmente inferior a los 6 meses (2,5 meses en nuestro caso) a pesar del tratamiento. Puesto que se trata de una enfermedad muy infrecuente no existen ensayos clínicos aleatorizados que compare la eficacia de diferentes esquemas terapéuticos en esta enfermedad.

El esquema de quimioterapia más empleado es el $\mathrm{CHOP}$ (ciclofosfamida, adriamicina, vincristina y prednisona) (6). En esta variante de LNH de fenotipo B no estaría justificado la adición del anticuerpo monoclonal anti-CD20 (rituximab), ya que las células tumorales generalmente no expresan CD20, salvo en los raros casos en los que dicho marcador esté presente.

Otros esquemas más agresivos de poliquimioterapia que se pueden emplear son el hyper-CVAD/HIDAC-MTX (ciclofosfamida, vincristina, adriamicina, dexametasona/dosis altas de ARA-C y metotrexate) o ICE (ifosfamida, carboplatino y etopósido) o incluso EPOCH (etopósido, vincristina, ciclofosfamida, doxorubicina y prednisona) (7) en los casos de sida.

En los pacientes con sida un correcto tratamiento antirretroviral (TARGA) es esencial en la estrategia terapéutica (8). Los pacientes con infección pasada o crónica para virus de la hepatitis $\mathrm{B}$ en el seno de los linfomas deben recibir lamivudina $100 \mathrm{mg} /$ día por vía oral, para evitar reactivaciones del virus, sobre todo si van a recibir rituximab. 


\section{Bibliografía}

1. Jaffe ES, Harris NL, Stein H, Vardiman JW. World Health Organization classification of tumors: Pathology and Genetics of tumours of haematopoetic and lymphoid tissues. Lyon, France: IARC Press, 2001.

2. Khosravi P, Pérez G. Linfoma B difuso de células grandes. Med Clin (Barc) 2006 [en imprenta].

3. Fisher RI, Shah P. Current trends in large cell lymphoma. Leukemia 2003; 17: 1948-1960.

4. Jaffe ES, Harris NL, Diebold J, Muller-Hermelink HK. World Health Organization classification of neoplastic diseases of the hematopoietic and lymphoid tissues. A progress report. Am J Clin Pathol 1999; 111: S8-S12.

5. Harris NL, Jaffe ES, Diebold J, Flandrin G, Muller-Hermelink HK, Vardiman JW, et al. The World Health Organization classification of neo- plastic diseases of the hematopoietic and lymphoid tissues. Report of the clinical advisory committe meeting, Airlie House, Virginia, November, 1997. Ann Oncol 1999; 10: 1419-1432.

6. Khosravi P. Linfoma intravascular. Med Clin (Barc) 2005; 124: 67-8.

7. Little RF, Pittaluga S, Grant N, Steinberg SM, Kavlick MF, Mitsuya $\mathrm{H}$, et al. Highly effective treatment of acquired immunodeficiency syndrome-related lymphoma with dose-adjusted EPOCH: impact of antiretroviral therapy suspension and tumor biology. Blood 2003; 101: 4653-9.

8. Carrieri MP, Pradier C, Piselli P, Piche M, Rosenthal E, Heudier P, et al. Reduced incidence in Kaposi's sarcoma and of systemic non-Hodgkin's lymphoma in HIV-infected individuals treated with highly active antiretroviral therapy. Int J Cancer 2003; 103; 142-4. 